Een bedrieglijke bijbal 


\section{Een bedrieglijke bijbal}

en 22 andere klinische lessen uit Huisarts \& Wetenschap

\section{Onder redactie van}

G.A. van Essen

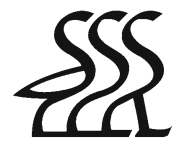

Bohn Stafleu van Loghum

Houten 2007 
CC Bohn Stafleu van Loghum, 2007

Alle rechten voorbehouden. Niets uit deze uitgave mag worden verveelvoudigd, opgeslagen in een geautomatiseerd gegevensbestand, of openbaar gemaakt, in enige vorm of op enige wijze, hetzij elektronisch, mechanisch, door fotokopieën of opnamen, hetzij op enige andere manier, zonder voorafgaande schriftelijke toestemming van de uitgever.

Voor zover het maken van kopieën uit deze uitgave is toegestaan op grond van artikel 16b Auteurswet $1912 \mathrm{j}^{\mathrm{o}}$ het Besluit van 20 juni 1974, Stb. 351, zoals gewijzigd bij het Besluit van 23 augustus 1985, Stb. 471 en artikel $17 \mathrm{Au}-$ teurswet 1912, dient men de daarvoor wettelijk verschuldigde vergoedingen te voldoen aan de Stichting Reprorecht (Postbus 3051, 2130 KB Hoofddorp). Voor het overnemen van (een) gedeelte(n) uit deze uitgave in bloemlezingen, readers en andere compilatiewerken (artikel 16 Auteurswet 1912) dient men zich tot de uitgever te wenden.

Samensteller(s) en uitgever zijn zich volledig bewust van hun taak een betrouwbare uitgave te verzorgen. Niettemin kunnen zij geen aansprakelijkheid aanvaarden voor drukfouten en andere onjuistheden die eventueel in deze uitgave voorkomen.

ISBN 9789031351565

NUR 870

Ontwerp omslag: Fredrik Helfrich, Deventer

Ontwerp binnenwerk: TEFF Typography

Automatische opmaak: Pre Press, Zeist

Bohn Stafleu van Loghum

Het Spoor 2

Postbus 246

3990 GA Houten

www.bsl.nl 


\section{Inhoud}

Voorwoord VII

Over de redactie IX

Mijn man kan niets meer onthouden...

Inleiding 1

Transient global amnesia 3

Diagnostiek 4

Behandeling 4

Beschouwing 5

Conclusie 5

Literatuur 5

$\begin{array}{ll}\text { Tussen allergieangst en corticosteroïdvrees } & 7\end{array}$

$\begin{array}{ll}\text { Inleiding } & 7\end{array}$

Methodologie 8

De rol van allergie bij constitutioneel eczeem 8

De effecten en bijwerkingen van corticosteroïden 9

Bespreking $\quad 10$

$\begin{array}{ll}\text { Literatuur } & 11\end{array}$

Eigen foto's: een wegwerpcamera bij chronische $\begin{array}{ll}\text { lage rugpijn } & 13\end{array}$

Inleiding 13

Chronische lage rugpijn $\quad 14$

Een wegwerpcamera: de patiënt op de foto 15

Eigen foto's in de zorg $\quad 15$

Conclusie 16

$\begin{array}{ll}\text { Literatuur } & 16\end{array}$

'Dokter, ik heb het niet zo op pillen' 17

Inleiding 17 
$\begin{array}{ll}\text { Methodologie } & 18 \\ \text { Het effect van topische NSAID's op pijnvermindering } & 19 \\ \text { Effect op de begeleidende symptomen } & 20 \\ \text { De bijwerkingen van topische NSAID's } & 20 \\ \text { Bespreking } & 22 \\ \text { Literatuur } & 23\end{array}$

Een leerling met een zweertje in de mond 25

Inleiding 25

Een eeuw later $\quad 28$

Beschouwing $\quad 30$

$\begin{array}{ll}\text { Literatuur } & 31\end{array}$

Once in a life time: de ziekte van Cushing 33

Betty $\quad 34$

Na de opname $\quad 39$

Conclusies $\quad 39$

Literatuur $\quad 40$

Valkuilen bij overleg over euthanasie $\quad 43$

Inleiding 43

Beschouwing $\quad 50$

Literatuur $\quad 52$

Een pessarium, alleen voor overdag 55

Inleiding $\quad 55$

Bespreking $\quad 57$

Indicaties voor pessariumgebruik overdag 58

Voorwaarden voor gebruik $\quad 58$

Meten en passen $\quad 59$

Literatuur $\quad 60$

Een angstig meisje met stemmen in haar hoofd 63

Bespreking $\quad 68$

$\begin{array}{ll}\text { Literatuur } & 71\end{array}$

Is elke excessief huilende zuigeling een huilbaby? $\quad 73$

Inleiding 73

$\begin{array}{ll}\text { Bespreking I } & 75\end{array}$

$\begin{array}{ll}\text { Bespreking II } & 77\end{array}$

Bespreking III $\quad 80$

Epiloog $\quad 80$

$\begin{array}{lr}\text { Literatuur } & 80\end{array}$ 
Tuberculose in de huisartspraktijk $\quad 83$

\begin{tabular}{ll} 
Inleiding & 83 \\
\hline & 83
\end{tabular}

Besmetting $\quad 87$

Onderzoek bij asielzoekers $\quad 88$

$\begin{array}{ll}\text { Klachten } & 88\end{array}$

Diagnostiek $\quad 89$

Behandeling $\quad 90$

Conclusie $\quad 90$

$\begin{array}{ll}\text { Literatuur } & 91\end{array}$

Wie zijn neus schendt... 93

Inleiding 93

Het varicellazostervirus: komen en gaan 95

Oogafwijkingen door het varicellazostervirus $\quad 95$

Wanneer is het oog aangedaan? 96

Wat te doen? $\quad 96$

Altijd een wakend oog $\quad 97$

$\begin{array}{ll}\text { Conclusie } & 97\end{array}$

$\begin{array}{ll}\text { Literatuur } & 97\end{array}$

Vitamine-D-deficiëntie, niet alleen bij migranten-

vrouwen $\quad 99$

Vormen en bronnen van vitamine D 100

Vitamine-D-deficiëntie 101

Migrantenvrouwen 101

$\begin{array}{ll}\text { Prevalentie } & 101\end{array}$

Diagnostiek 102

$\begin{array}{ll}\text { Therapie } & 102\end{array}$

Preventie 103

Conclusie 103

$\begin{array}{ll}\text { Literatuur } & 103\end{array}$

De nazaat van een kleurrijke horzel 105

Inleiding 105

Bespreking 106

Conclusie 108

$\begin{array}{ll}\text { Literatuur } & 109\end{array}$

Een bedrieglijke bijbal $\quad 111$

$\begin{array}{ll}\text { Inleiding } & 111\end{array}$

Beschouwing $\quad 112$

Conclusie $\quad 114$

$\begin{array}{ll}\text { Literatuur } & 114\end{array}$ 
Fibromyalgie, een gevoelig puntje

Inleiding

Classificatie en prevalentie

Pathofysiologie

Diagnostiek en differentiële diagnose

Behandeling

120

Prognose

Conclusie

Literatuur

Libidoverlies bij gebruik van de pil

Inleiding

Bijwerkingen van de pil

Effecten van de pilhormonen op libido

Libido en welbevinden

Conclusie

Literatuur

Perniones

Inleiding

Het klinische beeld van perniones

De behandeling van perniones

Literatuur

Een onschuldige atheroomcyste

Inleiding

Beschouwing

140

Conclusie

142

Literatuur

De ziekte van Weil, een rariteit maar toch relevant $\mathbf{1 4 5}$

Inleiding

Bespreking

Epidemiologie in Nederland

Serotypen en risicogroepen

149

Klinisch beeld

150

Conclusie

Literatuur

Bovenbuikklachten in de loop van de zwangerschap: HELLP voor de huisarts

Inleiding

Bespreking

Conclusie 
De saturatiemeter in de huisartsenpraktijk

Inleiding

159

Beschouwing

162

Literatuur

De vele gezichten van het colorectaal carcinoom

Inleiding

Wat voegt een anamnese toe?

170

Wat voegt het lichamelijk onderzoek toe?

171

Wat voegt laboratoriumonderzoek toe?

172

Conclusie

172

Literatuur

173

Over de auteurs

Register 


\section{Voorwoord}

Het leeuwendeel van de kennis die op het spreekuur of aan het ziekbed wordt gebruikt berust noodzakelijkerwijs op observationeel onderzoek.* In de hiërarchie van wetenschappelijk onderzoek staat de gerandomiseerde gecontroleerde trial (RCT) meestal bovenaan. RCT's kunnen kleine therapeutische effecten kwantificeren. Innovatie begint echter meestal met een casuïstische mededeling.

Vrijwel alle klinische lessen in deze bundel zijn zulke casuïstische mededelingen. Vaak over aandoeningen met een lage prevalentie, waarover nooit een NHG-Standaard zal verschijnen. Soms over een diagnostisch instrument, een aparte therapie of nauwelijks gebruikte farmacotherapie die in individuele gevallen heel goed werkzaam bleek.

De klinische lessen in deze selectie uit de afgelopen tien jaargangen Huisarts $\&$ Wetenschap hebben steeds een huisarts (in opleiding) als eerste auteur. Niet verwonderlijk, want de huisarts wordt vaak als eerste geconfronteerd met een bijzonder geval. En die huisarts kan ook het best de lessen trekken die leerzaam zijn voor zijn collega's. Elk hoofdstuk uit deze bundel is een feest om te lezen.

De traditie van de klinische les bestaat nog niet zo lang in Huisarts $\mathcal{E}$ Wetenschap. In 1998 besloot het bestuur van het Nederlands Huisartsen Genootschap op voorstel van de redactie van HEW om een jaarlijkse Casuïstiekprijs in te stellen voor de beste klinische les in die jaargang. De redactie ontwierp een cursus 'Schrijven van klinische lessen' en veel deelnemers aan die cursus hebben een bijdrage geleverd. Niet elk jaar kon de NHG-Casuïstiekprijs worden uitgereikt, maar alle prijswinnaars tot 2007 zijn opgenomen in deze bundel.

In de boekenreeks Huisarts \& Wetenschap verschenen eerder de bundels Palliatieve zorg en Kwalitatief onderzoek. Deze bundel klinische lessen vormt de feestelijke afronding van de vijftigste jaargang van $H \mathcal{E} W$.

Ted van Essen, interim-hoofdredacteur Huisarts \& Wetenschap

\footnotetext{
* Vandenbroucke JP. Niveaus van bewijskracht schieten tekort. Ned Tijdschr Geneeskd 2006;150:2485.
} 


\section{Over de redactie}

Ted van Essen is werkzaam als huisarts in Amersfoort en daarnaast verbonden als wetenschappelijk onderzoeker aan het Julius Centrum voor Gezondheidswetenschappen en Eerstelijnsgeneeskunde in Utrecht. Hij was voorzitter van het Nederlands Huisartsen Genootschap van 2000 tot 2004 en hoofdredacteur ad interim van Huisarts en Wetenschap van november 2006 tot 1 januari 2008. 